\title{
Tumor de células gigantes en cuarto metacarpiano: a propósito de un caso
}

\section{Giant Cell Tumors on the Fourth Metacarpal: about a case}

\author{
Alejandra Ortega Palacios ${ }^{1}$ Juan Carlos Márquez Ambite ${ }^{2}$ Tomasz Rumin Zbigniew ${ }^{3}$ \\ ${ }^{1}$ Médico Interno Residente de $5^{\circ}$ año de Cirugía Ortopédica y \\ Traumatología, Hospital Universitario Infanta Elena, Madrid, España \\ 2 Jefe de Sección de Cirugía de Mano, Codo y Muñeca, Hospital \\ Universitario Infanta Elena, Madrid, España \\ ${ }^{3}$ Médico Adjunto de Cirugía Ortopédica y Traumatología, Hospital

\begin{abstract}
Address for correspondence Alejandra Ortega Palacios, Médico Interno Residente de $5^{\circ}$ año de Cirugía Ortopédica y Traumatología, Hospital Universitario Infanta Elena, Madrid, España (e-mail: ale_op@hotmail.com).
\end{abstract} Universitario Infanta Elena, Madrid, España

Rev Iberam Cir Mano 2018;46:40-45.

\section{Resumen}

Palabras Clave

- Tumor de células gigantes óseo

- Metacarpiano

- Mano
Los tumores de células gigantes óseos en las manos son raros; presentamos un caso de un paciente con TCGO localizado en el cuarto metacarpiano tratado en dos tiempos quirúrgicos mediante resección en bloque de todo el hueso y reconstrucción con injerto de peroné vascularizado autólogo seguido de artroplastia metacarpofalángica. Tras un seguimiento postoperatorio de dos años y, a pesar de una recidiva cutánea y sinóstosis a nivel de la prótesis que puede precisar una nueva intervención, el paciente se encuentra libre de recidivas y satisfecho con los resultados obtenidos.

Hands are a rare location for giant cell tumors of the bone. In this article we discuss the case of a patient with a GCTB located on the fourth metacarpal treated in two surgical times. First, with an in bloc resection of the bone and reconstruction with autologous vascularized fibular graft followed by metacarpophalangeal arthroplasty. After a twoyears postoperative follow-up and, in spite of a cutaneous recurrence and synostosis at the level of the prosthesis that may require a new intervention, the patient is free of recurrence and satisfied with the results obtained.

\section{Introducción}

El tumor de células gigantes óseo (TCGO), es considerado una neoplasia localmente invasiva con elevada posibilidad de recurrencia local y con capacidad de malignizar y metastatizar, principalmente, a pulmón. Esta lesión se localiza, con mayor frecuencia, sobre la región epifisaria y metafisaria de huesos largos, preferiblemente en el siguiente orden: fémur distal, tibia proximal, húmero proximal y radio distal.

El TCGO tiene una incidencia de aproximadamente el $4 \%$ de los tumores óseos primarios y del 18\% de los tumores óseos benignos; sin embargo, su localización en los metacarpianos es rara, correspondiendo al $2 \%-4 \%$ de todos los TCGO. ${ }^{1}$ La mayoría de los TCGO aparece en la cuarta década de la vida, con ligera predominancia en el sexo femenino. La forma de presentación más habitual es mediante una lesión solitaria; menos del $1 \%$ son multicéntricas. La forma multicéntrica es más agresiva que la solitaria y, a diferencia de la solitaria, tiene predilección por los pequeños huesos de las manos y de los pies, además de presentarse en pacientes más jóvenes. La imagen radiológica clásica es una lesión radiolúcida, lítica, frecuentemente expansiva, con bordes bien definidos pero no esclerosos. Ocasionalmente presenta septos en su interior. ${ }^{2}$ En 1987 , Campanacci y Baldini crearon la clasificación radiológica de received

February 12, 2017

accepted

January 23, 2018

published online

April 10, 2018
DOI https://doi.org/

10.1055/s-0038-1639510. ISSN $1698-8396$
Copyright ๑ 2018 Thieme Revinter

Publicações Ltda, Rio de Janeiro, Brazil
License terms

c) $(1) \$$ 
esos tumores, dividiéndolos en tres grados según su tamaño, la afectación ósea y de partes blandas y su velocidad de crecimiento:

- Grado I: Tumor pequeño o de mediano tamaño que no insufla la cortical, con bordes bien definidos, rodeados de esclerosis y de crecimiento lento.

- Grado II: Tumor mediano o grande que insufla la cortical sin romperla, con bordes no tan bien definidos, sin esclerosis y de crecimiento rápido.

- Grado III: Tumor de gran tamaño que rompe la cortical, infiltra partes blandas y de crecimiento irregular. ${ }^{3}$

El aspecto macroscópico es de un tejido friable de color pardusco-marrón claro con zonas de hemorragia de color rojo oscuro. Las áreas de necrosis pueden parecer quiste-like, ya que presentan una imagen de cierta cantidad de fluido o material semisólido rodeado de una membrana. Histológicamente, contiene predominantemente células gigantes osteoclastoslike y células del estroma fusiformes. Las células gigantes osteoclastos-like son células patológicas con aspecto similar a los osteoclastos maduros y, al igual que esos, son las causantes de la rápida destrucción ósea en los TCGO. Los núcleos de esas células son redondos u ovalados y de tamaño uniforme. ${ }^{4,5}$ Entre las diferentes opciones de tratamiento para el TCGO de la mano encontramos el curetaje con o sin injerto óseo, la resección amplia y reconstrucción, la radioterapia, la amputación de la mano y la amputación de ese radio. El curetaje con o sin injerto óseo ha demostrado un $90 \%$ de índice de recurrencia de la lesión., 6,7

La recidiva de estos tumores en partes blandas es muy infrecuente (2\%). ${ }^{8}$ En la imagen radiológica, aparece un anillo de osificación periférica probablemente debido a metaplasia de las células tumorales. Esta imagen tan característica se considera patognomónica de recurrencia de TCGO en partes blandas. $^{8-10}$ El principal diagnóstico diferencial debe realizarse con la miositis osificante. ${ }^{10}$ Se ha propuesto que estas recurrencias podrían deberse a la implantación durante la cirugía o a diseminación secundaria por una fractura patológica. $^{11}$
En este artículo presentamos un caso de tumor de células gigantes óseo localizado en el cuarto metacarpiano de la mano derecha tratado en dos tiempos: el primer tiempo consistió en la resección en bloque del cuarto metacarpiano completo junto con escisión de tejidos blandos circundantes seguido de reconstrucción con autoinjerto vascularizado de peroné con isla cutánea; en el segundo tiempo se reconstruyó la cuarta articulación metacarpofalángica mediante prótesis de silicona.

\section{Caso Clínico}

Varón de 42 años que acude al Servicio de Urgencias de nuestro hospital por persistencia de dolor en $4^{\circ}$ metacarpiano de la mano derecha tras un traumatismo banal 10 días antes.

En ese momento, la exploración física era anodina, presentando únicamente dolor a la palpación de la cabeza del $4^{\circ} \mathrm{MTC}$ de la mano derecha. La imagen radiológica inicial mostraba una lesión lítica en la cabeza del $4^{\circ}$ metacarpiano sin afectación cortical (-Fig. 1a).

La RM fue informada como fractura patológica sobre lesión lítica que afectaba a la cabeza y el cuello del $4^{\circ}$ MTC sin alteración articular, presentando un tamaño de $2 \times 1 \mathrm{~cm}$, compatible con encondroma.

A los dos meses se observó empeoramiento tanto clínico como radiológico con aumento del dolor local a la palpación, tumefacción y limitación para la extensión del $4^{\circ}$ dedo.

En esa ocasión, la radiografía simple mostraba un aumento de la lesión con insuflación de la cortical ( - Fig. 1b).

Una nueva RM con gadolinio se informó como una lesión lítica insuflante en la zona epifisometafisaria distal del $4^{\circ}$ metacarpiano con marcado adelgazamiento cortical y probable rotura de la misma, además de afectación de partes blandas y derrame articular, con un tamaño craneocaudal de $28 \mathrm{~mm}$ y captación de gadolinio pudiendo corresponder a un tumor de células gigantes sin poder descartar otras posibilidades (-Fig. 1c).

Ante la posibilidad de un tumor de células gigantes óseo grado III de Campanacci y viendo la rápida evolución de la
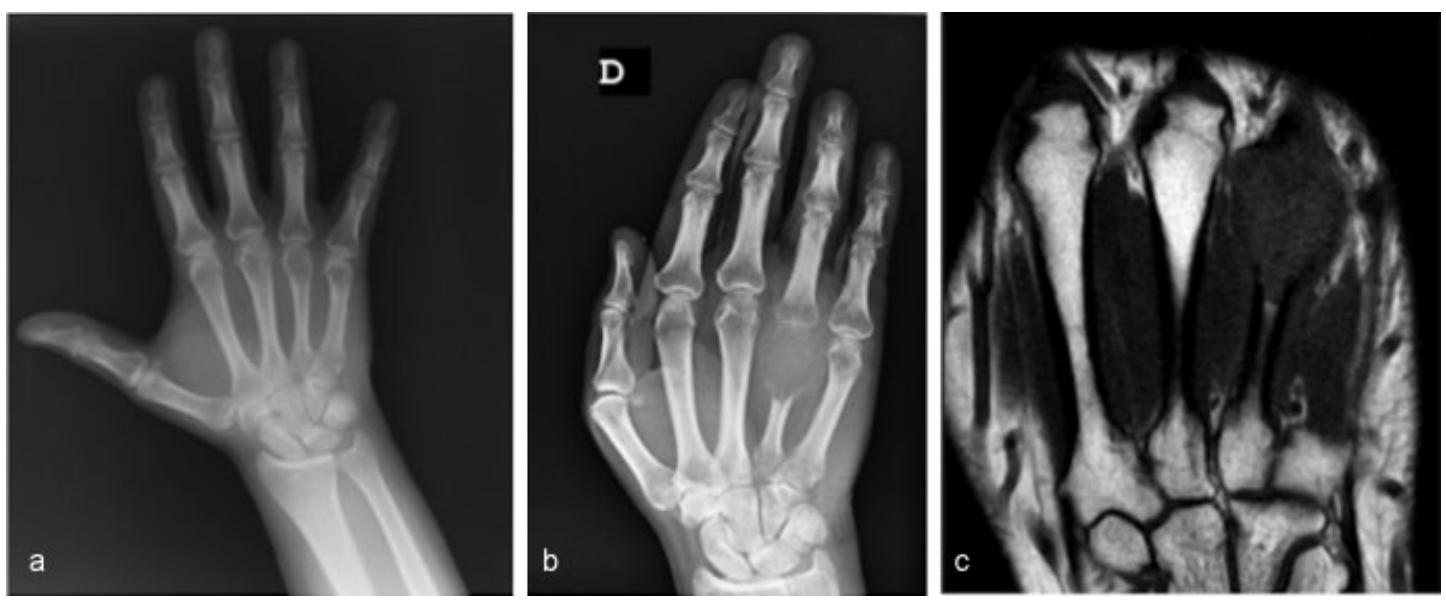

Fig. 1 (a) Lesión lítica en la cabeza del $4^{\circ}$ MTC de la mano derecha. (b) Empeoramiento radiológico evidente a los 3 meses. (c) Resonancia magnética con gadolinio que muestra una lesión lítica insuflante en la zona epifisometafisaria distal del $4^{\circ} \mathrm{MTC}$ con adelgazamiento cortical, además de afectación de partes blandas, con un tamaño craneocaudal de $28 \mathrm{~mm}$. 
enfermedad, se realizó una primera intervención quirúrgica para la toma de biopsia incisional de la lesión mediante abordaje palmar, con extracción de tejido de color rojo oscuro friable.

El estudio anatomopatológico de la muestra confirmó el diagnóstico de tumor de células gigantes óseo, por lo que en Abril de 2015 se inició el tratamiento quirúrgico en dos tiempos.

Tal como se menciona anteriormente, tras un preoperatorio adecuado incluyendo ecografía doppler de ambos miembros inferiores y del miembro superior derecho, el paciente fue sometido a una cirugía en dos tiempos.

En el primer tiempo se realizó la amputación completa del $4^{\circ}$ metacarpiano y tejidos blandos circundantes respetando los nervios, vasos sanguíneos y tendones ya que, debido a su rápido avance, en el momento de la intervención se observó la destrucción completa de dicho hueso. Seguidamente, se procedió a la reconstrucción con injerto osteocutaneo de peroné vascularizado autólogo de $6,5 \mathrm{~cm}$ de longitud e isla cutánea de $4 \times 4 \mathrm{~cm}$. Se realizó artrodesis ganchoso-peroné mediante placa y se fijó distalmente al $5^{\circ}$ metacarpiano y a la falange proximal del $4^{\circ}$ dedo mediante agujas de Kirschner. Además, los ligamentos colaterales metacarpofalángicos se conservaron y se reinsertaron al injerto de peroné con dos implantes Minilok Quickanchor (DePuySynthes) ${ }^{\circledR}$ con la finalidad de estabilizar la prótesis metacarpofalángica que se planeó utilizar en un segundo tiempo (-Fig. 2, - Fig. 3a).
A nivel de la muñeca, se hizo la anastomosis terminoterminal del pedículo peroneo a la arteria radial y a la vena cefálica.

Durante el postoperatorio, se apreció una buena evolución radiológica y congestión venosa de la isla cutánea del injerto, que mejoró progresivamente tras múltiples incisiones con inyecciones subcutáneas de heparina de bajo peso molecular, basándonos en el tratamiento aplicado en el trabajo de Pérez y col. ${ }^{12}$ (- Fig. 3b).

A los tres meses del primer tiempo quirúrgico, se inició el segundo basado en la recuperación de la movilidad de la articulación metacarpofalángica, mediante el implante de prótesis monobloque de silicona tipo Ascension (Medcom Tech) ${ }^{\circledR}$.

Tras finalizar el tratamiento quirúrgico, el paciente evolucionó de forma satisfactoria con la correcta integración del injerto de peroné y de la isla cutánea. Se retiró la inmovilización a las tres semanas del segundo tiempo quirúrgico y comenzó la movilización pasiva suave en su domicilio. Sin embargo, presentó cierta limitación en la movilidad del $4^{\circ}$ y $5^{\circ}$ dedos pero, por motivos personales, no inició la rehabilitación hasta dos meses después de la última intervención. Al inicio de la misma, el paciente presentaba una actitud espontanea del $4^{\circ}$ dedo en extensión de las articulaciones metacarpofalángica e interfalángica distal con flexión de $60^{\circ}$ de la articulación interfalángica proximal, que resultaba irreductible.
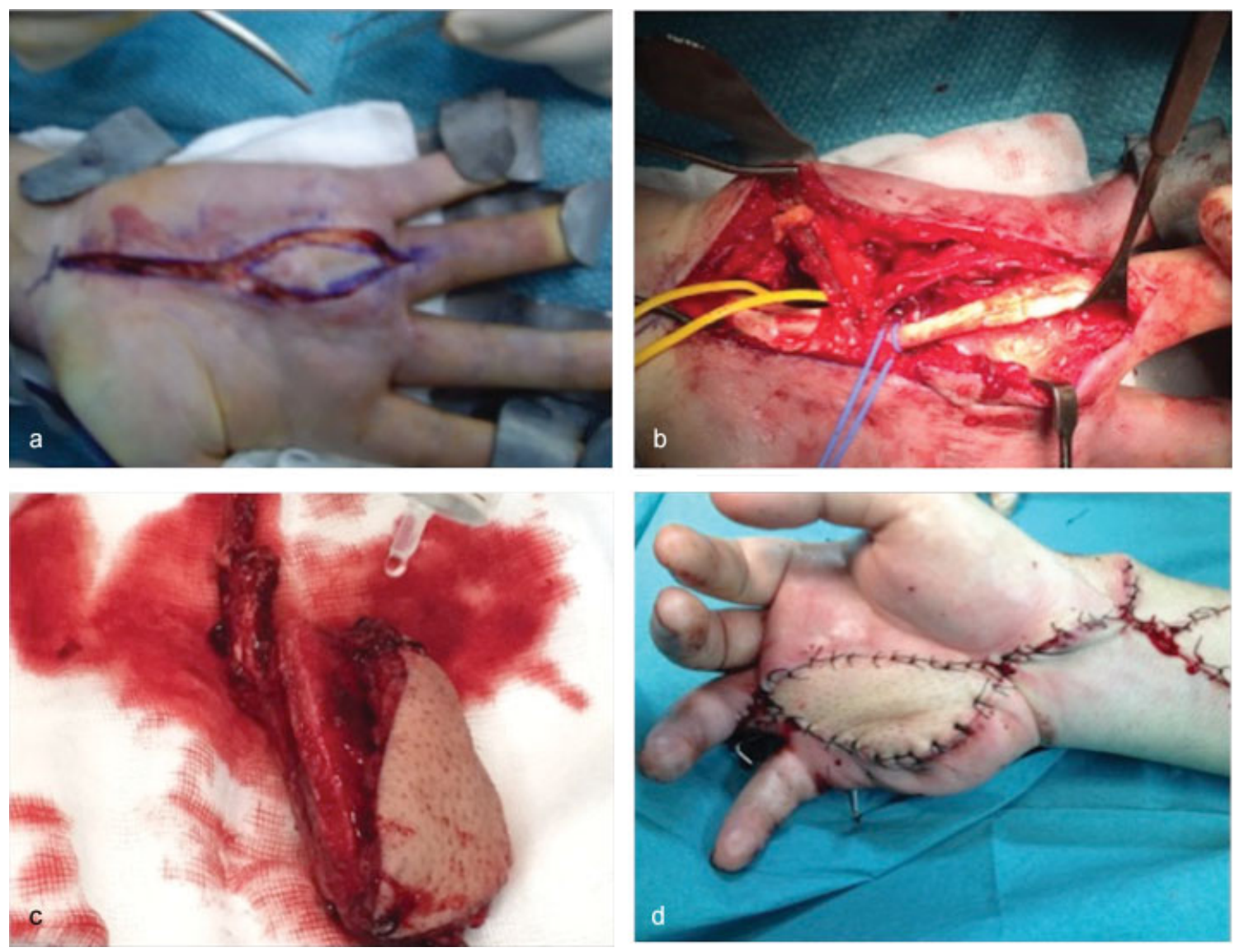

Fig. 2 (a) Abordaje quirúrgico volar sobre $4^{\circ} \mathrm{MTC}$ incluyendo la cicatriz de la toma de biopsia previa. (b) Se observa la tumoración bajo los tendones flexores del $4^{\circ}$ dedo. (c) Injerto de peroné vascularizado autólogo con isla cutánea. (d) Herida quirúrgica resultante. 

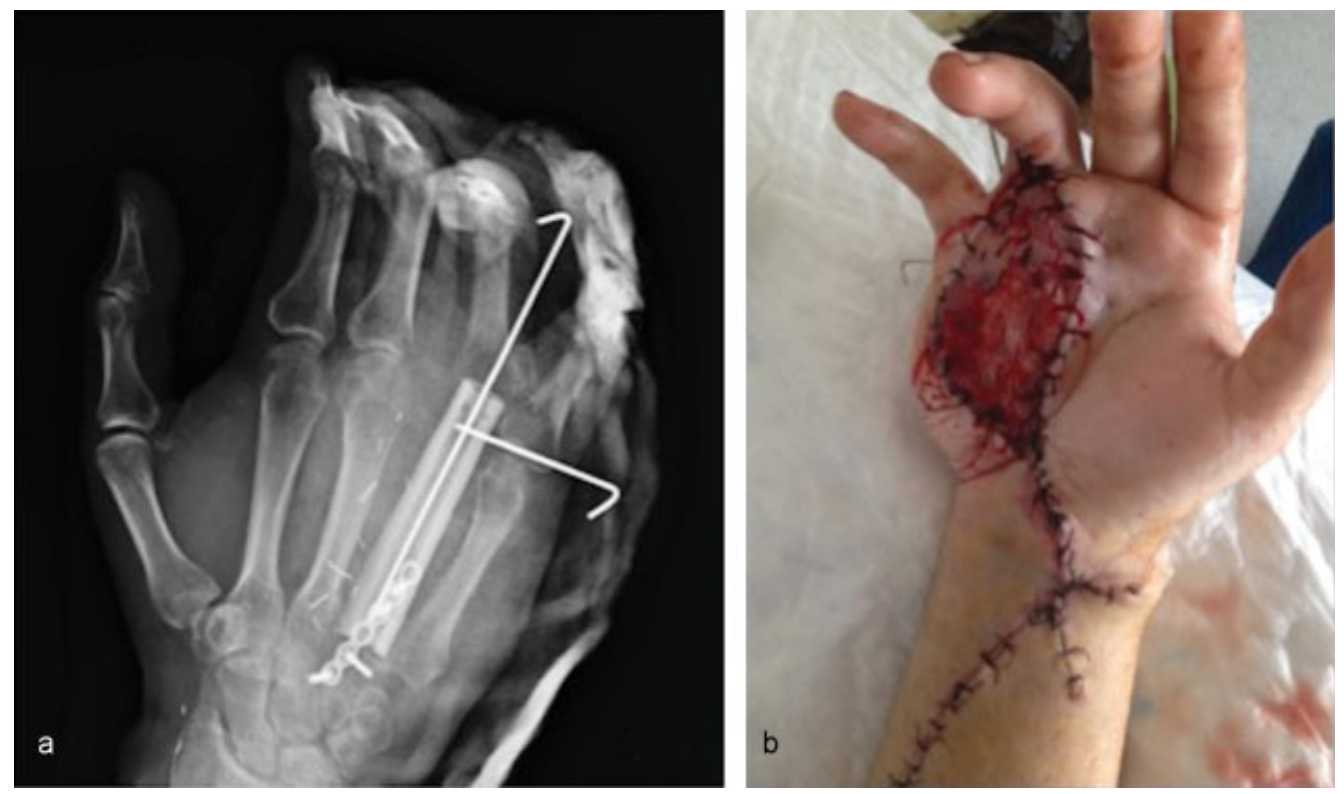

Fig. 3 (a) Rx simple postoperatoria en la que se observa el injerto de peroné fijado mediante 2AK y artrodesis ganchoso-peroné con placa de reconstrucción. (b) Congestión venosa postoperatoria de la isla cutánea tratada mediante múltiples incisiones e inyecciones subcutáneas de HBPM.

Además, en Enero de 2016 apareció una tumoración palmar de $3 \times 3 \mathrm{~cm}$ de aspecto rojo-violáceo a nivel de $3^{\circ}$ metacarpiano. Ante la sospecha de una recidiva cutánea, en Febrero de 2016 se realizó la exéresis en bloque de la lesión con márgenes amplios seguida de cobertura con injerto autólogo de piel de espesor completo procedente de la región inguinal. Durante la cirugía, se observó que la lesión respetaba la fascia palmar, los tendones flexores y los pedículos vasculonerviosos (-Fig. 4a, -Fig. 4b, -Fig. 4c, -Fig. 4d).

El estudio anatomopatológico confirmó el diagnóstico de recidiva cutánea de tumor de células gigantes con márgenes libres de lesión.

Tras esta última intervención, el paciente presentó buena evolución sin nuevas recidivas, reiniciando así la rehabilitación.

En la actualidad, el paciente ha finalizado el tratamiento rehabilitador con la siguiente exploración:

- Movilidad activa de muñeca igual a contralateral, con flexión de $75^{\circ}$, extensión de $50^{\circ}$, desviación cubital de $30^{\circ}$ y desviación radial de $20^{\circ}$.

- Rango articular de $1^{\circ}, 2^{\circ}$ y $3^{\circ}$ dedos completo, con pinza funcional entre el $1^{\circ}$ y $2^{\circ}$ dedos.

- Rigidez del $4^{\circ}$ dedo con ausencia completa de movilidad y clinodactilia cubital.

- Quinto dedo con flexoextensión pasiva completa de la articulación metacarpofalángica aunque la flexión activa se encuentra abolida por la rigidez del cuarto dedo. La articulación interfalángica proximal presenta un rango articular de $0^{\circ}-60^{\circ}$ reductible, y la articulación interfalángica distal con un rango de $0^{\circ}-80^{\circ}$.

- Sensibilidad conservada en todos los dedos.

En cuanto a la dinamometría con Jamar ${ }^{\circledR}$, el estado actual es el siguiente:
- Fuerza de puño de $10 \mathrm{~kg}$ en mano derecha y $30 \mathrm{~kg}$ en mano izquierda.

- Fuerza de pinza terminoterminal de $5 \mathrm{~kg}$ en mano derecha y $12 \mathrm{~kg}$ en mano izquierda.

Las últimas pruebas radiológicas realizadas muestran un proceso de calcificación capsular con sinóstosis a nivel de la prótesis metacarpofalángica, por lo que se le ha planteado al paciente la posibilidad de que en un futuro precise de una nueva intervención quirúrgica para revisión de la prótesis de silicona para mejorar el rango de movilidad, pero el paciente se encuentra satisfecho con el resultado actual por lo que, de momento, rechaza nuevas intervenciones (-Fig. 5).

\section{Discusión}

La mano es una localización poco frecuente para los TCGO. Debido a la baja incidencia de este tipo de tumor en la mano, la bibliografía actual es escasa. Goldenberg y col. ${ }^{6}$ realizaron un estudio de 218 casos de TCGO, de los cuales sólo 5 casos se localizaban en metacarpianos. Una de las mayores series de la bibliografía actual sobre TCGO en manos es el realizado por Averill y col. ${ }^{13}$ Consiste en un estudio multicéntrico que incluye 21 pacientes y 28 lesiones. En otros dos estudios sobre TCGO con 327 y 411 casos, los autores solo encontraron, respectivamente, 5 y 4 TCGO en la mano. ${ }^{14-16}$

De entre todos los tratamientos descritos, parece haber cierto consenso en pensar que, para los TCGO de los metacarpianos, el tratamiento de elección es la resección seguida de reconstrucción con alo- o autoinjerto de hueso, siendo el cirujano el que debe decidir el grado de resección indicado en cada caso. 

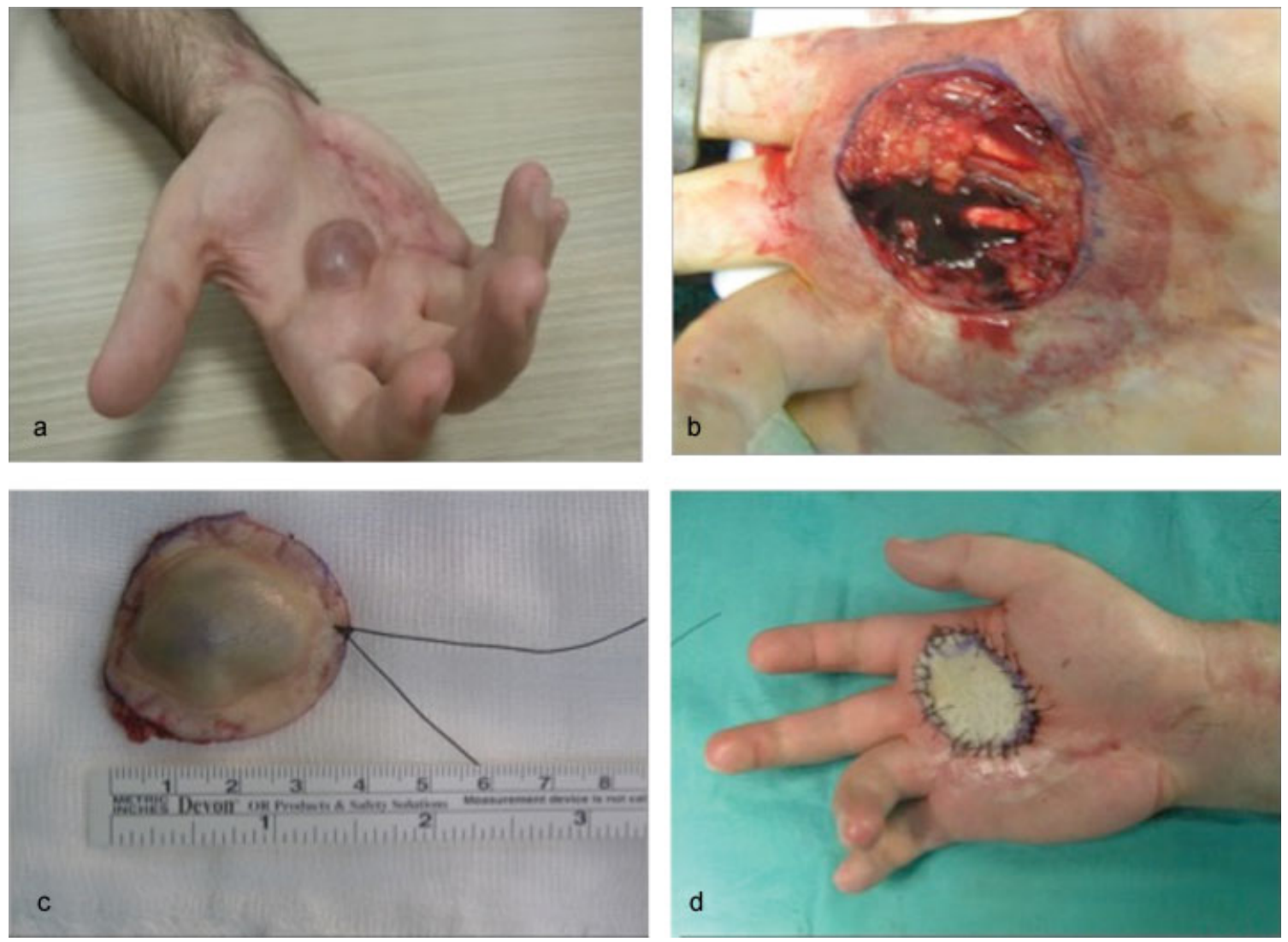

Fig. 4 (a) Tumoración volar de aspecto rojo-violáceo. (b) Lecho resultante tras resección de la lesión; se observa que respeta los paquetes vasculonerviosos y tendones flexores. (c) Pieza de resección de recidiva cutánea de TCG. (d) Autoinjerto de piel libre.
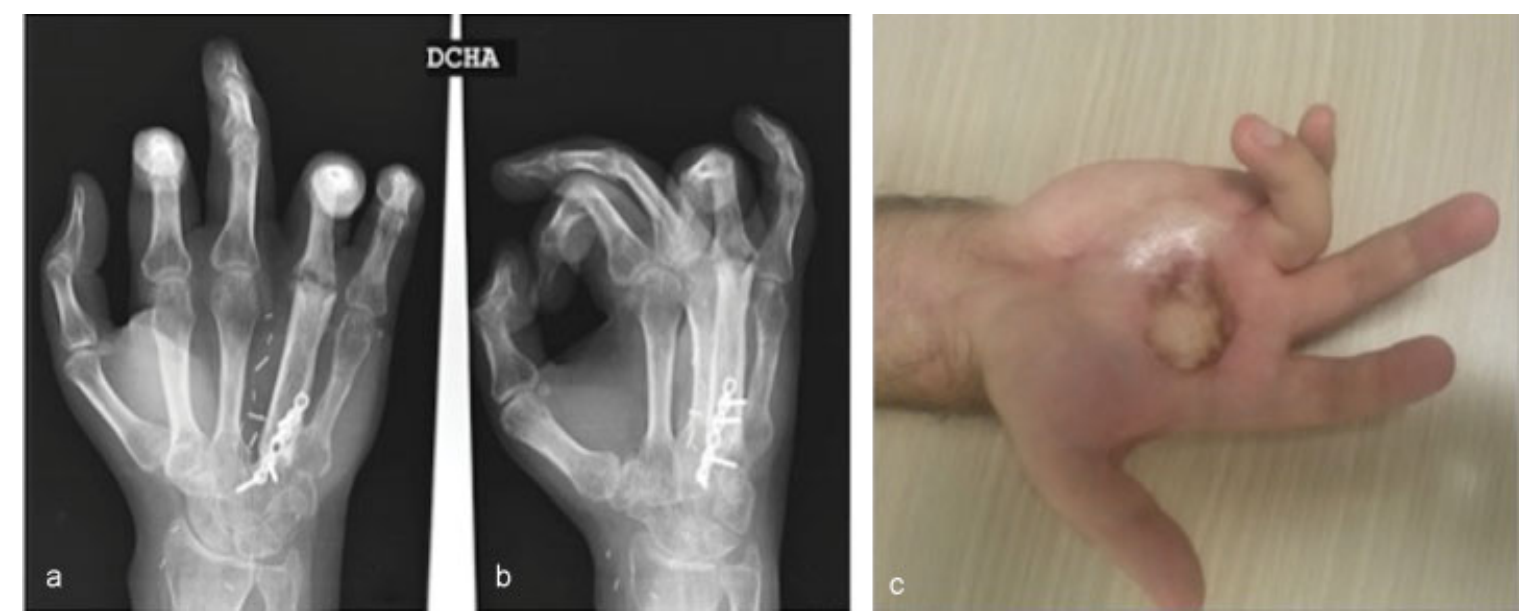

Fig. 5. (a y b) Imágenes radiológicas AP y oblicua en las que se observa la calcificación capsular con Sinóstosis a nivel de la prótesis de silicona metacarpofalángica. (c) Estado actual de la mano.

En nuestro caso, nos encontrábamos ante un paciente joven, sano y activo por lo que, basándonos en la bibliografía respecto al tratamiento de elección, y debido a la alta tasa de recidiva tras el curetaje, decidimos hacer una resección amplia y reconstrucción con autoinjerto de peroné vascularizado y prótesis de silicona con rigidez residual del $4^{\circ}$ dedo y ausencia de recidiva tumoral.
Conflicto de Intereses

Los autores declaran que no hay conflicto de intereses.

\section{Bibliografía}

1 Greenspan A, Remagen W. (2002) Miscelánea de tumores y lesiones seudotumorales. In: Tumores de huesos y articulaciones, Greenspan A, Remagen W,Editors Madrid, Marban 
2 Jones NF, Dickinson BP, Hansen SL. Reconstruction of an entire metacarpal and metacarpophalangeal joint using a fibular osteocutaneous free flap and silicone arthroplasty. J Hand Surg Am 2012;37(02):310-315

3 Aguilar Ezquerra A, López Subías J, Lillo Adán M, Peguero Bona A. Tratamiento de tumores de células gigantes. Rev Cuba Ortop Traumatol 2015;29(01):1-7

4 Biscaglia R, Bacchini P, Bertoni F. Giant cell tumor of the bones of the hand and foot. Cancer 2000;88(09):2022-2032

5 Mendenhall WM, Zlotecki RA, Scarborough MT, Gibbs CP, Mendenhall NP. Giant cell tumor of bone. Am J Clin Oncol 2006; 29(01):96-99

6 Goldenberg RR, Campbell CJ, Bonfiglio M. Giant-cell tumor of bone. An analysis of two hundred and eighteen cases. J Bone Joint Surg Am 1970;52(04):619-664

7 Matev B, Georgiev H, Georgiev GP. Giant cell tumor of the fourth metacarpal: Case report and literature review. J Radiother Med Oncol 2012;17(02):73-77

8 Lee FY, Montgomery M, Hazan EJ, Keel SB, Mankin HJ, Kattapuram S. Recurrent giant-cell tumor presenting as a soft-tissue mass. A report of four cases. J Bone Joint Surg Am 1999;81(05):703-707
9 Murphey MD, Nomikos GC, Flemming DJ, Gannon FH, Temple HT, Kransdorf MJ. From the archives of AFIP. Imaging of giant cell tumor and giant cell reparative granuloma of bone: radiologic-pathologic correlation. Radiographics 2001;21(05): 1283-1309

10 Cooper KL, Beabout JW, Dahlin DC. Giant cell tumor: ossification in soft-tissue implants. Radiology 1984;153(03):597-602

11 Bond JR, Cooper KL. Musculoskeletal case of the day. Soft-tissue implant of giant cell tumor. AJR Am J Roentgenol 1993;160(06): 1328-1329

12 Pérez M, Sancho J, Ferrer C, García O, Barret JP. Management of flap venous congestion: the role of heparin local subcutaneous injection. J Plast Reconstr Aesthet Surg 2014;67(01):48-55

13 Averill RM, Smith RJ, Campbell CJ. Giant-cell tumors of the bones of the hand. J Hand Surg Am 1980;5(01):39-50

14 Saikia KC, Bhuyan SK, Ahmed F, Chanda D. Giant cell tumor of the metacarpal bones. Indian J Orthop 2011;45(05):475-478

15 Campanacci M, Baldini N, Boriani S, Sudanese A. Giant-cell tumor of bone. J Bone Joint Surg Am 1987;69(01):106-114

16 Dahlin DC. Caldwell Lecture. Giant cell tumor of bone: highlights of 407 cases. AJR Am J Roentgenol 1985;144(05):955-960 